\title{
Root Suppletion and the Theory of Allomorphic Locality
}

\author{
Leila A Lomashvili ${ }^{1}$ \\ ${ }^{1}$ Department of English \& Humanities, Shawnee State University, OH, USA \\ Correspondence: Leila A Lomashvili, Department of English \& Humanities, Shawnee State University, Portsmouth, \\ $\mathrm{OH}, 45662$, USA. E-mail: llomashvili@ shawnee.edu
}

Received: December 22, 2018

Accepted: January 28, 2019 Online Published: February 13, 2019

doi:10.5430/wjel.v9n1p34

URL: https://doi.org/10.5430/wjel.v9n1p34

\begin{abstract}
The paper investigates the root suppletion phenomena with its direct relation to the theory of allomorphic locality as it is couched in the Distributed Morphology (DM) framework (Halle \& Marantz 1993, 1994) and its recent developments. The paper covers the suppletion phenomena of two varieties, those conditioned by the number of an internal argument and tense-aspect-mood (TAM) features of functional heads merging above roots. The empirical data is brought up to support the main claim that the suppletion of verbal roots can be conditioned not only by the most local elements such as the number of the internal argument, but it can also be triggered by the TAM features of the functional heads which are outside of the XP boundary where the roots are merged (Harley et al. 2009, Bobaljik 2012, Harley 2015 among others). To account for the TAM-conditioned suppletion, the paper is using the phase-theoretic approach following Chomsky (1999) and Embick (2010) by positing a variety of non-cyclic heads merging above roots that render the interaction between TAM features and roots possible even though some of the intervening heads between roots and these features may be overtly realized. The paper arrives at the conclusion that the suppletion can still be triggered by the local material converging with other authors mentioned above.
\end{abstract}

Keywords: root suppletion, number, internal argument, XP domain, TAM features

\section{Introduction}

The locality domains restricting the insertion of various Vocabulary Items (VIs) into the computed syntactic nodes in the post-syntactic component of grammar have been the subject of intense research in the framework of Distributed Morphology recently. Among some core ideas, the locality domains for the application of various morphological rules and where exactly they apply in the post-syntactic component have been covered in a variety of literature such as Arad (2003, 2005), Harley, et al. (2009), Bobaljik (2012), Embick (2010), Marantz (2013), Moscal (2015 a-b) among others. This paper continues the strand of research started in the above works as well as in Harley et al. (2009) and Choi \& Harley (C\&H, in press) on the root suppletion, using the node sprouting analysis (Marantz 2015, C \& H) at the PF branch of grammar. This paper concurs with some of the previous research on the idea of the $\mathrm{X}^{0}$ conditioning domain for non-overlapping suppletion (Bobaljik 2012), and that the Vocabulary Items (VIs) for suppleted roots are inserted in certain syntactic environments under the complex $\mathrm{X}^{0}$. In addition, the paper argues that Bobaljik's $\mathrm{X}^{0}$ delimiting domain is too restrictive to account for the certain cases of suppletion, especially those which are triggered by Tense, Aspect, and Mood (TAM) features of functional heads since these heads are merged higher in the derivation (above the $\mathrm{X}^{0}$ domain) where the number features of internal arguments are specified and are the most frequent suppletion triggers cross-linguistically.

The paper uses the empirical data of the two languages, Georgian and Mengrelian, both being part of the Kartvelian language family, to illustrate dissociated morpheme insertion (renamed as node-sprouting in $\mathrm{C} \& \mathrm{H}$ ) as a rule-governed grammatical pattern, which can apply when the suppletion trigger and the root are in local relation, and the node-sprouting applies as the post-syntactic operation. Following Harley et al. (2009) and Bobaljik and Harley (Forthcoming), this paper shows that suppletion is not the result of Agree relation, which is always established in syntax but rather represents locally conditioned allomorph selection at Late Insertion. The paper also argues that root suppletion sensitive to the internal argument number or Tense-Aspect-Mood (TAM) features of verbs is a separate morphological reflex from pronominal clitics or agreement, which mark the person and number features of verbal arguments (Nash-Haran 1992, Halle \& Marantz 1993). Some previous research has shown that agreement markers and suppletion of roots are independent processes, and this is supported by empirical evidence. Generally, morphological agreement in DM has been treated as a variety of dissociated morpheme insertion for quite some time 
(Halle \& Marantz 1993, Bobaljik 2008). Sprouted $\mathrm{Agr}^{0}$ nodes are inserted according to language-specific sprouting rules, and subsequently realized by agreement markers as $\mathrm{C} \& \mathrm{H}$ and others show (p.2). This paper following Bejar (2002), Lomashvili \& Harley (2011), and McGinnis (2014) shows that these agreement markers are triggered by the phi-features of the functional heads such as the variety of the $\mathrm{v}^{0}$ heads and $\mathrm{T}^{0}$, and they are marked separately on the verb with distinct morphological markers independent of the suppleted roots. The paper argues that the suppletion is conditioned by the interpretable features as opposed to the formal plural marking of verbal arguments, which is always uninterpretable (Harley 2015).

The rest of paper is organized as follows: Section 1.1 overviews the main points of the prior research on suppletion phenomena across various languages; Section 2 presents the empirical base of the suppleted verbs in terms of the internal argument number; and Section 3 is analyzing these data in terms of cyclic-theoretic account and node-sprouting at the PF interface; Section 4 presents and analyzes the empirical base of TAM feature-conditioned suppletion, and finally, Section 5 concludes.

\subsection{Theories of Locality Effects and Suppleted Allomorphy}

The paper takes several theories of allomorphic locality as a starting point to elucidate the locality domains for the interaction between suppletion triggers and roots. Embick (2010) develops a comprehensive theory of local conditioning of morphological items by focusing on the linear adjacency as a crucial notion in the morphologically-conditioned allomorph selection. Linear adjacency is required for an item to affect the choice of another VI while structurally intervening material may still be present iff they are null. Embick argues that such null nodes can be 'pruned' during the vocabulary insertion, and hence, they do not block the conditioning of VIs by other items in the prosodic unit. He also assumes that if the intervening material is overtly realized, they do block the conditioning of the node merged higher in the derivation assuming the bottom-up derivation, head-to-head movement, and the phonological realization of VIs at the PF interface. For example, if $a$ and $b$ heads are non-cyclic heads merged above the root in (1), they will not send the complement structure for PF processing and can still trigger root suppletion even though these heads are overtly realized. However, if the cyclic head $c$ is merged higher in the derivation, it cannot trigger suppletion because this head will send the complement off for the PF processing as soon as it is merged:

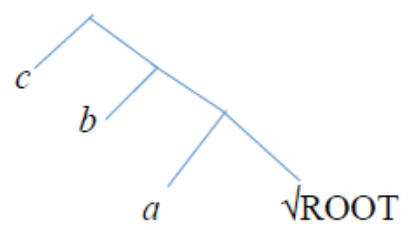

Thus, the root will not be accessible for suppletion if $a$ and $b$ are overtly realized and the $c$ head is a cyclic head, according to Embick (2010).

Another important proposal that the paper is utilizing for the treatment of suppleted verbs is Harley et al. (2009) observation that the intransitive suppleted verbs in Hiaki (Uto-Aztecan language spoken in Arizona) is conditioned by the number of the underlying object which appears as a surface subject of these intransitives. They argue that all intransitive verbs undergoing suppletion in this language are underlyingly unaccusative, which means that they cannot project an external argument. It appears that syntactically unaccusative structures cannot combine with the applicative head either, and this is shown by the applicative constructions which are very productive with the transitive verbs while impossible with the unaccusative roots. Harley et al. use the applicative diagnostics to show that the applicative morpheme -ria is unable to combine with the suppleted roots of unaccusative verbs since the latter are syntcatically unaccusative structures. They also show that the applicative morpheme by contrast can easily be combined with the transitive verbs, which typically project the external argument.

Bobaljik (2012) posits the locality domain conditioning the insertion of the lexical heads in comparative adjectives as the $\mathrm{X}^{0}$ complex head, and that allomorph selection can be restricted within XP boundary, and this generalization is true when the verbal root suppletion is triggered by the number of the internal argument. He considers a large array of empirical data of comparatives from a variety of languages and comes to the conclusion that the suppletion in comparative adjectives is quite local reducing the conditioning domain of suppletion to the complex $\mathrm{X}^{0}$ head. However, we show that the theory is highly restrictive when considering that the triggering element of verbal 
suppletion is TAM features. This paper therefore argues for the conditioning domain of suppletion to be outside of the XP in which the verbal root undergoes change and develops the locality theory of root conditioning within the cyclic theory of heads broadly construed for the derivation of words as XPs.

Moskal (2015 a-b)' s treatment of local conditioning of noun roots in K'et, on the other hand, utilizes the notion of cyclic heads from Embick (2010) and Bobaljik (2012)'s $\mathrm{X}^{0}$ locality domain for suppletive allomorphy of comparative adjective roots and proposes a second cyclic head merging above roots as an upper bound for allomorph conditioning. In the following structure, she argues that the \# head merging above the category-defining $n$ head, which is also regarded as cyclic (Marantz 1997, Embick 2010 among others) sends the complement for processing at the PF rendering the $\mathrm{K}$ (case head) incapable to affect the root suppletion in those nouns:

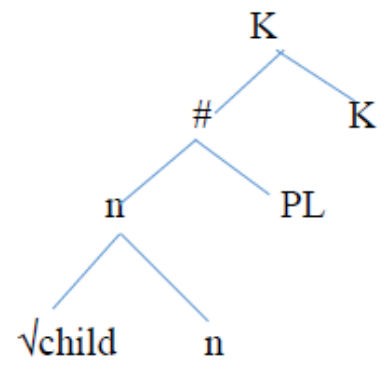

Moskal (2015a) consequently delimits the upper boundary of allomorph conditioning in the word level syntax within the complex $\mathrm{X}^{0}$ head and shows that this bound should not exceed a XP arriving at a very similar conclusion as Bobaljik's conclusion mentioned above.

By far the most distinctive account of allomorph conditioning has been proposed in Choi \& Harley (C\& $\mathrm{H}$, in press) by covering a large empirical base of Korean honorific marking and root suppletion triggered by these elements. They show that the hierarchical locality is relevant to allomorph conditioning and that the allomorph selection in case of competition of two VIs depends on the locality of features conditioning the insertion of more local allomorph than the less local one when the Subset Principle does not apply. Here is the generalization they arrive at:

(3) Local Allomorph Selection Principle

If two vocabulary items are in competition, and the Subset Principle does not apply, then vocabulary item conditioned by a more local feature blocks the vocabulary item conditioned by the less local feature (C\&H, p.4).

C\&H also give evidence against Bobaljik (2012), Moskal (2015a), and Merchant (2015) among others, who develop more restrictive theories of allomorph conditioning, and then add the node-sprouting analysis (aka dissociated morpheme insertion) of Korean subject honorification by the post-syntactic merger of the $\operatorname{Hon}^{0}$ head with the little $\mathrm{v}^{0}$ head as illustrated in the following trees:

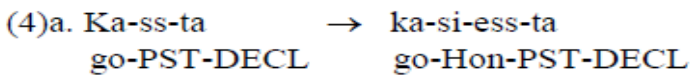

b. C on the last phase

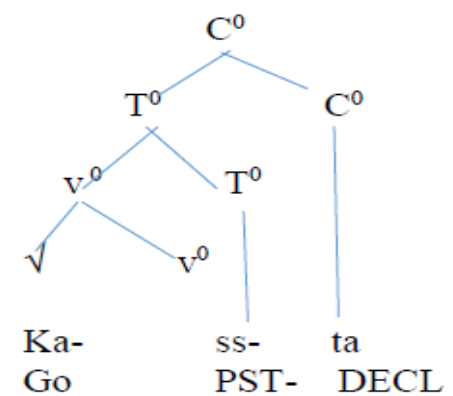

(C \& H: 15)

c. After node-sprouting

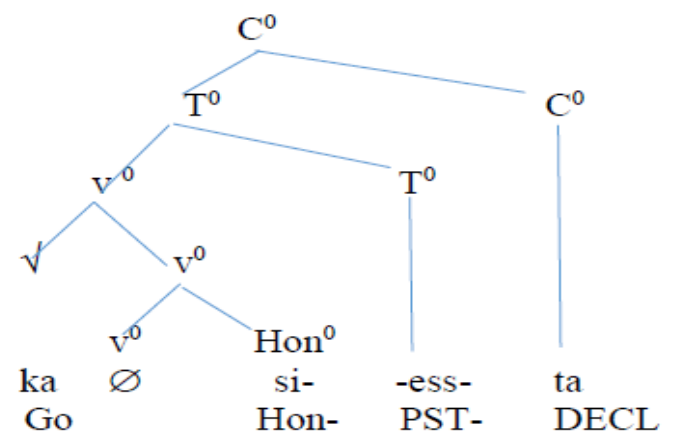

This kind of dissociated morpheme insertion is a very common procedure at the PF respecting the structural locality of the items such as $\mathrm{v}^{0}$ and $\mathrm{Hon}^{0}$ heads in (4). The paper utilizes a similar account of local conditioning of the root 
from the item merging as a result of the node-sprouting, in this case the Num ${ }^{0}$ head. See Section 3 for the similar account of root suppletion as a result of node-sprouting at the PF.

\section{Empirical Data of Verbal Root Suppletion in Terms of Number}

About 10 transitive verbs in Georgian supplete for the internal argument number. When this argument is a non-count, group, or simply plural noun, it triggers root suppletion as illustrated with the following set of transitive structures:

(5)

\begin{tabular}{|c|c|c|}
\hline $\begin{array}{l}\text { a. xe-m } \\
\text { tree-erg } \\
\text { 'the tree grew a leaf.' }\end{array}$ & $\begin{array}{l}\text { potoli } \\
\text { leaf.sg }\end{array}$ & $\begin{array}{l}\text { moiba. } \\
\text { grew.pl }\end{array}$ \\
\hline $\begin{array}{l}\text { b. xe-m } \\
\text { tree-erg }\end{array}$ & $\begin{array}{l}\text { potl-eb-i } \\
\text { leaf.-pl-nom }\end{array}$ & $\begin{array}{l}\text { moisxa. } \\
\text { grew.pl }\end{array}$ \\
\hline $\begin{array}{l}\text { c. tq'e-m } \\
\text { forest-erg }\end{array}$ & $\begin{array}{l}\text { potoli } \\
\text { leaf.pl }\end{array}$ & $\begin{array}{l}\text { moisxa. } \\
\text { grew.pl. }\end{array}$ \\
\hline $\begin{array}{l}\text { d. xe-eb-ma } \\
\text { tree-pl-erg }\end{array}$ & $\begin{array}{c}\text { potl-eb-i } \\
\text { leaf-pl-nom }\end{array}$ & $\begin{array}{l}\text { moisx-es. } \\
\text { grew.pl-S.pl }\end{array}$ \\
\hline
\end{tabular}

The example shows how non-count noun potoli 'leaf' can have a singular form but be interpreted as a group noun as in (5c) and condition the insertion of the plural root or 'grow.pl' $-S X A$ while the same noun can have the singular interpretation as in (5a), and the root of the verb will be the one matching the singular internal argument that is 'grow.sg' $-B M$ - . It is evident that the morphological conditioning of the root happens due to the local relation of the plural argument with the root. (5d) is interesting in that it shows that besides the internal argument number triggering the suppletion of the root, the number of the external argument is marked at the end of the template with the suffix - es (Aronson, 1990, p.86). Note that in (5a), the agreement marker is $-a$ due to the singular number of the external argument xe 'tree' in the third person. This empirical evidence supports the locality constraint, which delimits the domain of the root suppletion by the internal argument but never by the external argument. In Section 3, we show how structural adjacency accounts for this pattern, and that root suppletion can still be considered as an agreement of the internal argument with the verb. It is also notable that the following pattern of the external argument marking is impossible:

(6)

$\begin{array}{lcr}\text { a.* xe-eb-ma } & \text { potoli } & \text { moib-es } \\ \text { tree-pl-erg } & \text { leaves.pl } & \text { grow.sg-3S.pl } \\ \text { 'trees grow leaves.' } & & \\ & & \\ \begin{array}{l}\text { b. xe-eb-ma } \\ \text { tree-pl-erg }\end{array} & \text { potoli } & \text { moisx-es } \\ \text { trees grow leaves.' } & \text { leaves.pl } & \text { grow.pl-3S.pl }\end{array}$

The external argument triggering the insertion of the clitic -es at the end of the singular root moibes 'grow' does not generate an acceptable verbal form due to plural interpretation of the noun potoli 'leaves' which conditions the insertion of $\sqrt{ } S X A$ - plural root allomorph in this context. Therefore, (6b) is an acceptable form as opposed to the (6a).

There are additional 9 verbs in Georgian whose roots are suppleted according to the internal argument number, and among these verbs, the internal argument is a group noun formally resembling the singular noun but interpreted as plural and causing root-internal changes. Here is the set: 


\section{(7) Singular}

a. dasma

b. datsema

c. mobma

d. q'vana

e. deba

f. gdeba

g. kvla

h. gdeba

i. gatexva

Plural
dasxma
dasxma
mosxma
c'asxma
sxma
reka
xotsa
q'ra
damtvreva

'make someone sit'
'assail/attack someone'
'grow the fruit'
'take someone somewhere'
'build' (Old Georgian)
'lead cattle to field'
'kill, massacre'
'throw away'
'break' (Aron

(Aronson, p. 242-243).

This set shows that the majority of verbs suppleted for the internal argument number are not like 'light' verbs with bleached semantics as often argued in the literature (Embick \& Halle 2005 among others), but they are core vocabulary of the language the majority of which represents agricultural terms. One characteristic form in the set is the root $-S X A$, which can be combined with a variety of viewpoint aspectual markers, which are referred to as preverbs ( $P v b$, Aronson, p. 40) inserted in the pre-base position and followed by the pre-radical vowels ( $P V$, Aronson, p.41) $i-, e-, a-$, etc., and creating a variety of argument structures. Now observe the following set of the suppleted roots $^{1}$ :

(8)
a. Dato-m
bavshv-eb-i
skam-ze
da-sx-a
D-erg
kids-pl-nom
chair-on
Pvb- $\varnothing$-sit-3S.sg

'Dato made kids sit down on the chair.'
b. mgl-is
xrova
sopel-s
da-e-sx-a
tav-s.
wolf-gen
pack- $\varnothing$
village-dat
Pvb-PV-assail.pl-3S.sg
one-dat.REFL
'The pack of wolves assailed the village.'
uxvad
copiously
da-i-sx-a.
Pvb-PV-grow.pl-S3.sg
c. broc'eul-ma
naqopi
pomegranate-erg
fruit
'The pomegranate tree grew the fruit copiously.'

In (8a), the bound root triggered by the plural count noun bavshvebi 'kids' merged as an internal argument with the root triggers the plural root $\sqrt{ } S X A$, which does not combine with the pre-radical vowel while in (8b), the pre-radical vowel $e_{-}$, marking passive voice and reciprocal verbal structures, combines with the plural root, which is conditioned by the internal argument sopeli 'village' and interpreted as a group noun (Aronson, p. 380). In (8c) though, the internal argument interpreted as plural noun triggers the suppletion of root, and the PV in this verb is another passive voice marker $i$ - (Aronson, p. 377). The same VI inserted in the roots of all three structures creates a variety of meanings by combining with various pre-radical vowels, and the preverbal aspectual markers marked at the very beginning of the verbal template. As explained below, the root allomorph $-S X A$ - for the plural internal arguments looks like an elsewhere item in the set of roots used to express the plural meaning of the internal argument, and this is due to structural adjacency as explained in Section 3. The next section will present the data of suppleted verbs for their subject number which is also amenable to the same kind of analysis as the data of the verbs suppleted for the object number.

\subsection{Suppletion Data of Intransitive Verbs}

A few verbs from (7) and some unique roots can supplete for the plural number of the agentive argument, which structurally corresponds to the internal argument but crucially none of these arguments illustrated in (9) is an external argument:

\footnotetext{
1 These sentences were given by the native speaker consultant during the interview scheduled on June $12,2018$.
} 
(9)

\begin{tabular}{|c|c|c|}
\hline a. bavshv-i & skam-ze & da-jd-a. ${ }^{1}$ \\
\hline kid-nom & chair-on & Pvb-sit.sg-3S.sg \\
\hline \multicolumn{3}{|c|}{ 'The kid sat down on the chair.' } \\
\hline b. bavshv-eb-i & skam-eb-ze & da-sxd-nen. \\
\hline kid-pl-nom & chair-pl-on & Pvb-sit.pl-3S.pl \\
\hline \multicolumn{3}{|c|}{ 'The kids sat down on the chairs.' } \\
\hline $\begin{array}{l}\text { c. vashl-i } \\
\text { apple-nom }\end{array}$ & $\begin{array}{l}\text { chamo-vard-a } \\
\text { Pvb-fell.sg.-3S.sg }\end{array}$ & $\begin{array}{l}\text { xi-dan. } \\
\text { tree-from }\end{array}$ \\
\hline \multicolumn{3}{|c|}{ 'An apple fell down from the tree.' } \\
\hline $\begin{array}{l}\text { d. vash-eb-i } \\
\text { apple-pl-nom }\end{array}$ & $\begin{array}{l}\text { chamo-cvivd-nen } \\
\text { Pvb-fell.pl-3S.pl }\end{array}$ & $\begin{array}{l}\text { xi-dan. } \\
\text { tree-from. }\end{array}$ \\
\hline \multicolumn{3}{|c|}{ 'The apples fell down from the tree.' } \\
\hline e. vaza- $\varnothing$ & ga-tq'd-a. & \\
\hline $\begin{array}{l}\text { vase-nom } \\
\text { 'The vase broke.' }\end{array}$ & Pvb-broke.sg-3S.sg & \\
\hline f. vaz-eb-i & da-i-mtvr-a. & \\
\hline $\begin{array}{l}\text { vase-pl-nom } \\
\text { 'The vases broke.' }\end{array}$ & vb-PV-broke.pl-3S.sg & \\
\hline
\end{tabular}

These data is consistent with the structural position of the subject as an internal argument of the verb construction. The external arguments of the verbs in (9) are marked with the nominative case like the subjects of unaccusative verbs go and arrive. ${ }^{2}$ None of these verbs in (9) can be classified as unergative either whose only argument resembles the external argument of transitive verbs marked with the nominative, ergative, and dative cases in the three TAM series- Present, Aorist, and Perfect respectively (Aronson, p.40). In Section 2.3, we show how these arguments are moved from VP-internal position to the specifier of $\mathrm{vP}$ and then TP to check the relevant features of the unaccusative $\mathrm{v}^{0}$ and the $\mathrm{T}^{0}$ heads to finish the derivation. The focal point here is that the suppletion of verbal roots is still triggered by the number of the internal argument as shown in the pattern. One interesting morphological feature of the data is that the NP in (8e-f) does not trigger the plural agreement marker -es or -nen but instead it triggers the singular subject agreement $-a$ as opposed to the subjects in $(9 \mathrm{~b}, \mathrm{~d})$ where the plural subjects trigger both the suppletion of the roots as well as the plural agreement marker at the end of the verbal template. The possible explanation of this morphological idiosyncrasy is that the verb 'daimtvra' broke.pl has the meaning of broke into pieces, which already has an internal argument 'pieces' causing the suppletion of the root while 'the vase' is an external argument occupying the position of the non-overt internal argument and from that position it cannot trigger the suppletion of the roots nor the subject agreement marker. The derivation of this structure with the explanation of the external argument plural marking will be discussed in Section 3.3.

\subsection{Data of Suppletion and Agreement in Ditransitive Constructions}

Some of the roots shown in (5) and (8) can be used in the ditransitive frame by adding an additional applicative argument to the argument structure of transitive verbs that already consists of the external argument and the theme/patient theta roles. The suppletion of these roots still is triggered by the internal argument while the plural agreement marker -es is the agreement marker of the third person plural external argument but not crucially of the benefactee/goal applicative argument projected between the internal and external arguments:

\footnotetext{
1 The glossing of various verbal functional heads includes the following notions entirely taken from Aronson's Readers' Grammar such as the following: Pvb stands for the aspectual preverb, which can also mark directionality, PV stands for the pre-radical vowel marking version, voice or transitivity, S.sg stands for singular subject prson marking, nom for the morphological nominative and erg for ergative case, dat for the dative, and Nom with the capital letter stands for the nominalizing marker which is often a circumfix marked on both sides of the root, etc.

${ }^{2}$ Note that Georgian has a split ergative system of the case marking which entails the nom-erg-dat marking for the subjects of the transitive verbs across Present, Aorist, and the Perfective series and dative marking of objects in the present series and nom marking of objects in Aorist and Perfective.
} 
(10)
a. Laura-m
bavshv-s
Laura-erg
kid-dat
'Laura threw away the toy for the kid.'
b. Laura-m
Laura-erg
kid-pl-dat
'Laura threw away the toy for the kids.'
bavshv-eb-s
$\begin{array}{ll}\text { c. mshobl-eb-ma } & \text { bavshv-s } \\ \text { Parent-pl-erg } & \text { kid-dat } \\ \text { 'Parents threw away the toy for the kid.' }\end{array}$
d. Laura-m bavshv-s
Laura-erg kid-dat
satamasho-eb-i
toy-pl-nom
'Laura threw away the toys for the kid.'
satamasho
toy- $\varnothing$
satamasho
toy- $\varnothing$
satamasho-eb-i
toy-pl-nom
gada-u-gdo.
Pvb-PV-throw.sg
gada-u-gdo.
Pvb-PV-throw.sg

This set shows that suppletion tracks the number of an internal argument satamasho 'toy' while the applicative argument cannot change the root in (10b) even though it is plural. The applicative argument cannot trigger neither suppletion of the root nor the agreement marker at the end of the verbal template. The applicative argument cannot trigger root suppletion and the agreement due to the structural position this argument occupies in the extended verbal projection, which will be explained in Section 2.4 below. The external argument number is affecting the spellout of the verb-final agreement slot realized as $-e s$ in other transitive and intransitive structures above. This will be explained by the structural position of the external argument and its locality to the $\mathrm{T}^{0}$ head, which checks its phi-features on the local external argument, and the morphological component spells out only the agreement features of the closest argument as shown in Bejar (2003) and Lomashvili \& Harley (2011). Overall, the suppletion pattern above is consistent with the cross-linguistic pattern such as in Hiaki and Hopi (Harley 2011), which shows a very similar conditioning of the verbal roots by the internal argument number.

\section{Analysis: Verbal Suppletion as Competition}

The paper adopts a generative view of root suppletion with its emphases on the competition between root allomorphs competing for the insertion into the computed nodes as other morphologically conditioned allomorphs do (Harley 2011). In Section 3, we show how the locality-based view of suppletion nicely accounts for all allomorphic conditioning presented in the previous section and conclude that apparent cases of suppletion are always triggered by the merger of the internal argument with the root within the XP boundary while the external arguments can only trigger the verbal agreement but crucially don't cause any changes to roots. The applicative arguments, on the other hand, fail to trigger the root change as well as the agreement due to cyclic-based constraints and the distance from the root. The next section will explain the root suppletion in (5)-(8).

\subsection{Analysis of Root Suppletion: Internal Arguments as Triggers}

In the cases where the suppletion of the verbal root is the result of the plural number of the internal argument, the widely circulated view on the conditioning domain of suppletion being the maximal projection XP cannot be maintained wholesale (Harley, et al. 2009, Bobaljik 2012, Moskal 2015 a-b among others). In all cases illustrated in (5), (7), (9), and (10), regardless the initial structural position of the internal argument whether it is an external or internal argument it is the closest argument XP to the root or $\mathrm{Num}^{0}$ specified for [+plural] that conditions the insertion of the plural root morphemes. This is illustrated in the following: 
(11) Internal argument as a trigger of suppletion

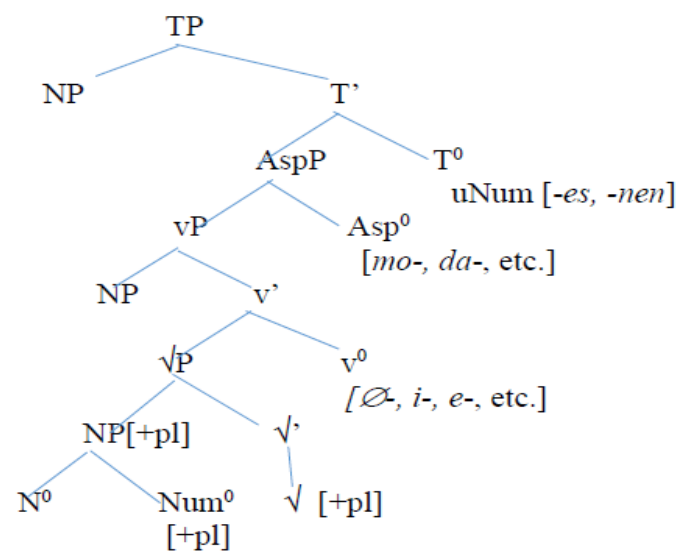

Assuming the bottom-up derivation of the syntactic structure illustrated above in (5), the verbal root starts the derivation at the bottom of the tree, and the internal argument is merged in the specifier of the $\sqrt{ } \mathrm{P}$, but at the PF interface, the node-sprouting adds the $\mathrm{Num}^{0}$ head to the $\mathrm{N}^{0}$ head, and when the number is specified for [+plural] this causes the insertion of the plural root at the PF into the computed node. After the merger of the vP, which is the verbalizer, a new NP can be merged in the specifier as an external argument, but the number of this argument cannot affect the root because when the $\mathrm{v}^{0}$ head is specified for [+ transitive] this head will be sending off the complement for the PF processing, and the root will not be accessible for the external argument number to trigger suppletion.

The verbal root starts under the $\sqrt{ } \mathrm{P}$, and then head moves to the verbal functional heads such as $\mathrm{v}^{0}$ whose phonological exponent depends on the features of $\mathrm{v}^{0}$ whether it will be [+transitive], [-transitive], or any relevant value. After this step, the complex verbal head moves to the $\mathrm{Asp}^{0}$ and $\mathrm{T}^{0}$, the letter bearing UAgr feature and checked by the closest noun merged in the derivation. In the case of the VP grow (the leaves), the two VIs competing for the insertion into the root node will be the following:

(12)

VIs for the VP ' $g r o w$ (the leaves)'

a. $\sqrt{ }$ GROW $\leftrightarrow-s x-/\left[\mathrm{Num}^{0}=[+\mathrm{pl}] / \mathrm{v}^{0}\right.$

b. $\sqrt{ }$ GROW $\leftrightarrow-b m-/$ elsewhere

In the construction where a non-count or plurally-interpreted group noun is merged, the structural description for VI in (12a) is met and the suppletive variant of the root is inserted. It is also assumed that the verbal root will be accessible for the suppletion conditioned by the internal argument number since the root is in the same derivational cycle with the number of the noun conditioning suppletion.

For the subject of intransitive verbs triggering the suppletion of verbal roots, it can be assumed that it starts out as an internal argument of the root moving up to the spec of $\mathrm{vP}$ whose head is a verbalizer but this $\mathrm{v}^{0}$ head does not send off the structure for processing at the PF interface because it is not a cyclic or a phase head in a sense of Chomsky (1999). Thus, the verbal root will be accessible for suppletion from the NP, which is specified for the [+ plural], and as a syntactic primitive merges with the $\mathrm{Num}^{0}$ as the result of node-sprouting at the PF. From the specifier of NumP, it will move up to the spec of vP whose head is specified for [- transitive] feature and due to this specification, the NP specified for [+ plural] will check the case feature that is licensed for the subjects of intransitive verbs. This will ensure that the subject does not move to the canonical external srgumnt position, which is argued to be the spec of VoiceP (Kratzer 1994, Pylkkanen 2002). Thus, the locality of the suppletion-triggering NP marked with the [+plural] feature still ensures that the suppletion will change the verbal root: 
(13) Suppletion in intransitive structures

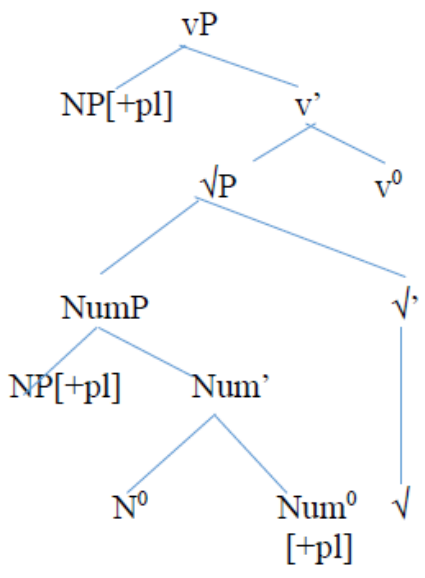

The primary morpho-syntactic domain that demarcates the boundary between the trigger of suppletion and the verbal root does not exceed the cyclic $\mathrm{X}^{0}$ head that sends off the structure to the PF interface for processing, and structurally this head may merge later in the derivation than what is shown in (13). It is notable though that the interaction between the allomorphs is permitted beyond the first XP in which the verbal root merges with the internal argument specified for the [+plural] as shown in the above tree, and we therefore concur with Harley et al. (2009) and Choi \& Harley in recognizing the boundary for the interaction outside of the first XP projecting from the root. The next section will explain the interaction between the suppletion trigger and the verbal root in applicative constructions.

\subsection{Analysis of Suppletion in Applicative Constructions}

As seen in (10), the applicative argument cannot trigger neither root suppletion nor the agreement at the end of the verbal template when the goal argument is specified for the plural feature. The reason why the applicative argument is unable to trigger the suppletion of the verbal root is that the cyclic head of the high VAPPLIC sends off the complement structure for the processing at $\mathrm{PF}$, and the root is no longer accessible for suppletion to the number of the applicative argument merged in the specifier of the high vPAPPLIC. McGinnis (2001) develops a detailed account of high and low applicatives in terms of phases high applicative being a phase while low applicative is not. Although we don't develop our theory of allomorphic locality in terms of phases, the idea that certain $\mathrm{v}^{0}$ heads may be sending the complement for PF processing is not new, and the high applicative $\mathrm{v}^{0}$ head is one of the cyclic heads shown in (11). It is also assumed that all ditransitive verbs suppleted in Georgian for the internal argument number and also adding the high applicative argument are not sensitive to the number of this argument.

As for the plural agreement marking at the end of the verbal template, the high applicative argument fails to trigger this kind of agreement either even when it is marked with the plural, morpheme $-e b$, and the external argument with the singular as in (10c). It can be assumed that the high applicative argument is accessible to check the phi-features of the $\mathrm{T}^{0}$ head, which arguably is specified for the v-set agreement markers (Bejar 2002), but the external argument is more local to the $\mathrm{T}^{0}$ head than the applicative argument, and the external argument checks the above features first before the applicative argument. At the PF, it is the features of the external argument that are given advantage for spellout, and they are realized as [-nen,-es] as shown in (10). Thus, the morpho-phonological interface of the syntactic derivation with the suppleted verbal roots is accounted for with the cyclic-theoretic analysis of the allomorphic interaction. ${ }^{1}$

\footnotetext{
${ }^{1}$ Before moving on the explanation of TAM features as possible triggers of suppletion, it is necessary to note the active/passive voice nominalizations that bear on the issue of the local domains of suppleted roots. The notable difference between the active and passive voice nominals in Georgian is that the root embedded in the active voice nominal can only derive the plural meaning with the exclusion of the singular meaning while the passive voice nominal can derive both singular and plural meanings based on the number feature of the internal argument as shown in (14) and (15):
} 


\section{Locality domains and suppletion in terms of TAM features}

Veselinova $(2003,2006)$ provides the list of languages where the roots of certain number of verbs supplete for the features of the $\mathrm{T}^{0}, \mathrm{Asp}^{0}$ and $\operatorname{Mood}^{0}$ functional heads merging in the derivation. Both Georgian and Mengrelian has a set of such verbs which lack certain conjugation paradigms, which are referred to as screeves in the literature (Aronson 1990, Harris 1981 and others).

The next section will present the data of the suppleted verbs in these languages, and Section 3.2 will analyze the locality domains for the interaction between these features, the functional heads that bear these features and the roots in relation to these features.

\subsection{Data of Suppleted Verbs in Terms of TAM Features}

The verbs in Georgian have 4 major patterns of conjugation (Aronson, p. 40), each of these patterns having its own unique characteristics in terms of the argument structure they project, morphological complexity as well as the ability to form 11 conjugation paradigms referred to as screeves. These screeves are organized by the tense, aspect, and mood features and are separated into the 3 series: Present, Aorist, and Perfective in Georgian. Mengrelian, another Kartvelian language, has 4 series from which 3 are the same as in Georgian and the additional $4^{\text {th }}$ series is called Subjunctive. First observe the series structure in Georgian for an expository reasons to understand the suppletion across the three series:

Table 1. Series and screeve structure in Georgian

\begin{tabular}{lll}
\hline Present Series & Aorist Series & Perfective Series \\
\hline Present & Aorist & Present Perfect \\
Imperfect & & Pluperfect \\
Present Subjunctive & Optative & Conjunctive Perfect \\
Future & & \\
Conditional & & \\
Future Conjunctive & & \\
\hline
\end{tabular}

(14) Active voice nominal

$\begin{array}{lc}\text { a. *m-bm-oiar-e } & \text { xe } \\ \text { Nom-grow.sg-Nom-stem.formant }{ }^{1} & \text { tree } \\ \text { 'fruit-bearing tree' } & \\ \text { b. m-sxm-oiar-e } & \text { xe } \\ \text { Nom-grow.pl-Nom-stem.formant } & \text { tree } \\ \text { 'fruit-bearing tree' } & \\ \text { (15) Passive voice nominal } & \\ \begin{array}{l}\text { a. mo-bm-ul-i } \\ \text { Nom-grow.sg-Nom/pass-nom }\end{array} & \text { naq'opi } \\ \text { 'grown (sg) fruit' } & \text { fruit.sg } \\ \text { b. da-sxm-ul-i } & \\ \text { Prev-grow.pl-Nom/pass-nom } & \text { naq'opi } \\ \text { 'grown (pl) fruit.pl }\end{array}$

'grown (pl) fruits'

The active voice nominal in (14a) fails to derive the structure based off of the singular root because the only overt argument this nominal projects is $x e$ 'tree,' and presumably this argument is projected as an external argument due to the 'active meaning' of the derived structure, and this argument cannot trigger the suppletion of the singular root since it is closed off from the root by the cyclic boundary and the complement of the head that licenses the external argument is sent off for the PF processing at this derivational point. Therefore, only the form matching the plural number of the non-overt internal argument (which possibly can be naqopi 'fruit') is (14b). The passive voice nominal of the same root can generate the structures matching two kinds of interpretation of the group noun naqopi 'fruit' that is projected as an internal argument of the root. Therefore, both (15a-b) are acceptable derivations for the passive voice nominal, and this again shows the interaction between the number of the internal argument and the suppletion of the root. 
Three screeves in the Present series form the Present subseries and another three screeves form the Future subseries. The suppletion is often triggered by the tense feature separating the Present Subseries root used for the present series screeves from the root used in the Future subseries screeves. Often the different root appears in the Aorist series, and the same lexical primitive carries over the Perfect series screeves. Now observe the empirical data in (16):

(16) Georgian TAM-conditioned suppletion patterns in term

\begin{tabular}{|c|c|c|c|}
\hline $\begin{array}{l}\text { Present } \\
\text { a. vambob }\end{array}$ & $\begin{array}{l}\text { Future } \\
\text { vitq'vi }\end{array}$ & $\begin{array}{l}\text { Aorist } \\
\text { vtkvi }\end{array}$ & $\begin{array}{l}\text { free translation } \\
\text { 'I say it' } 1 \text { ' }\end{array}$ \\
\hline b. dz'evs & - & idva & 'laying down' \\
\hline c. mimakvs & c'aviyeb & c'aviye & 'I take it' \\
\hline d. momakvs & movitan & movitane & 'I bring it' \\
\hline e. davdivar & moval & movedi & 'I come' \\
\hline f. vshvrebi & vizam & vkeni & 'I do it' \\
\hline
\end{tabular}

Several verbs even supplete in terms of the aspect distinguishing the perfective from imperfective actions by means of the suppleted roots as shown in the following:

(17)
Imperfective
a. vadz'lev
b. vsvam
c. vumzer//vuq'ureb

\author{
Perfective \\ miveci \\ davlev \\ shevxede
}

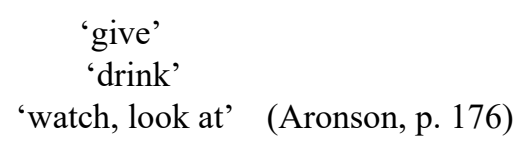

In this set, imperfective forms are all of the Present series Present screeve while perfective forms are of the Aorist $(17 \mathrm{a}, \mathrm{c})$ and Future Perfect screeves (17b). The notable feature of these suppleted roots is that they all are used in the Aorist and Perfect series once they replace the root used in the Present series or Present subseries screeves.

Mengrelian also has a set of high frequency verbs which supplete for the TAM features as illustrated in the following:

\section{(18) Suppleted verbal forms}

Present Future

a. v/pxek

b. mevuli/mevurk

c. vokork

d. michkun

dovpxoduk
vulu/vurk
okobuapuk
machkbvenuapu(n)

$\begin{array}{cc}\begin{array}{c}\text { Aorist } \\ \text { dovxodi }\end{array} & \begin{array}{c}\text { Perfective } \\ \text { domixunun }\end{array} \\ \text { mevbrti } & \text { milun } \\ - & - \\ - & -\end{array}$

$\begin{array}{cc}\begin{array}{c}\text { Subjunctive } \\ \text { donovpxunuek } \\ \text { nobvek }\end{array} & \text { 'sit' } \\ \text { nokobuen } & \text { 'go' } \\ \text { nom(b)chkve(n) } & \text { 'wnow' }\end{array}$

Kajaia 2001: 121-140)

Although these forms are multi-morphemic, and the bound roots are not separated from other functional material in this set, we can still state that the suppleted forms in the Future subseries and the Aorist and Perfect series are phonologically distinct from the Present subseries forms. The next section will explain the derivation and locality constraints on the allomorphic conditioning of roots in these structures.

\subsection{The Analysis of TAM Feature-Conditioned Suppletion}

The main question arising about the suppleted roots and the defective conjugation paradigms of verbs shown in (16)-(18) are: what type of morpho-syntactic conditions prompt the insertion of the suppleted roots into the paradigm and is the trigger of the suppletion complies to certain locality constraints so that the interaction between roots and

\footnotetext{
${ }^{1}$ The roots in these suppletive forms are boldfaced for the reader to have a clear idea how the suppletive pairs differ from each other phonologically. This convention will be used for all Georgian forms for the rest of the paper following Aronson's grammatical description of Georgian.
} 
the functional material is allowed in one derivational cycle? This section will attempt to answer these questions.

In (16) -(18), some frequently used verbal vocabulary items such as 'give' and 'take' fill their defective conjugation paradigms with the distinctive set of roots, which in their extended projection select a small set of aspectual markers (PV) and person clitics for their subjects as in (16c) for 'take.' It is assumed that the functional heads merged above roots define which set of clitics will be selected for particular verbs. For example, the root $\sqrt{ } \mathrm{TAKE}-A K V$ in the Present selects the m-set person clitic for its dative subject and $m i$ - preverbal marker at the beginning deriving the following form for the Present Imperfective and other screeves: ${ }^{1}$

$$
\begin{gathered}
\text { a. Present } \\
\text { mi-m-akv-s } \\
\text { Pvb-1S-have-3O.sg } \\
\text { 'I am taking it (somewhere).' } \\
\text { b. Future Perfective } \\
\text { c'a-v-i-r-eb } \\
\text { Pvb-1S-PV-take-TH } \\
\text { 'I will take it (somewhere).' } \\
\text { c. Aorist series } \\
\text { c'a-v-i-r-e } \\
\text { Pvb-1S-PV-take-Aor } \\
\text { 'I took it.' } \\
\text { d. Perfective series } \\
\text { c'a-m-i-r-ia } \\
\text { Pvb-1S-PV-take-scr. } \\
\text { 'I have taken it (apparently).' }
\end{gathered}
$$

As seen from (19), the change in root entails the change in the person clitic from the m-set to v-set the latter being the marker of agentive external arguments projected by transitive verbs. Note that the external arguments in the aspectually-conditioned split ergative case system like that of Georgian are marked with the nominative case in Present series, ergative in Aorist and Dative in Perfective. This pattern of the case marking can be observed for the verb 'take.' An interesting feature of the Perfective series is that the suppleted root for the Future, Aorist, and Perfect series combines with the different set of person clitics for subjects: v-set for Future and Aorist while m-set for the Perfective series. It's notable that the subjects of all transitive verbs take m-set clitics in Perfective series, and our conclusion is that it is the series features that affect the licensing of the argument case feature, and the latter in its turn affects the selection of the person clitic for these verbs. The root on its own cannot be responsible for the licensing of any case feature on the verbal arguments or person clitics. Rather it is the morpho-syntactic features of the functional heads built above roots that are specified for such features, and the insertion of the pre-radical vowels filling the pre-base slot, person clitic or the $P V$ (preverbal aspectual marker) are conditioned by the features on these functional heads.

Now the question about the locality of the suppletion trigger with the root can be answered. We assume that the TAM feature(s) causing suppletion should be in the same derivational cycle as the root and in fact this is true for the suppleted roots and the TAM features. Looking at the bottom-up derivational cycle in (20), the root starts out at the bottom from the $\sqrt{ } \mathrm{P}$, and it moves to the verbalizing head that can be realized as a version, applicative, or transitivity marker. The assumption is that among the TAM-suppleted roots all verbs select non-transitive argument structures with the nominative or dative subjects and objects, and these arguments are not canonical external subjects therefore assuming a variety of non-cyclic vPs merged in these structures. The consequence of such argument selection is that when $\mathrm{Asp}^{0}$ and $\mathrm{T}^{0}$ are merged after the $\mathrm{v}^{0}$ head, none of these heads will be sending the structure off for PF processing therefore allowing the interaction between these features and the roots that are suppleted in the mentioned series and subseries. The structure illustrating the locality constraints on the suppletion in Future, Aorist, and Perfective series can be sketched as in the following:

\footnotetext{
1 Bejar (2002) distinguishes two sets of agreement clitics: v-set and the $\mathrm{m}$-set the former triggered by the nom-ergative arguments and the latter by dative or accusative case argument.
} 


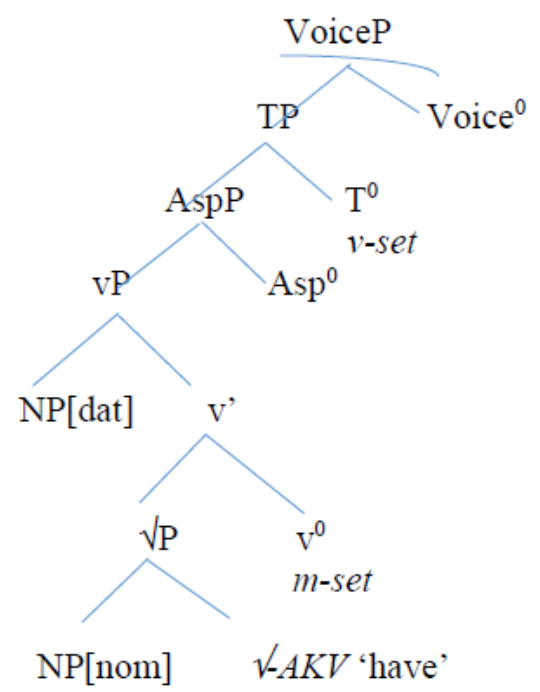

For the suppletion of the verbal root, the limiting domain would then be CP rather than vP. This can be supported with the observation that all forms in (16)-(17) project internal arguments in the subject position with only exception of the ditransitive 'give,' but the latter licenses the low applicative vP whose head may not be considered a cyclic head following McGinnis (2001), and even this $\mathrm{v}^{0}$ head does not send the complement for PF processing so that the root will be accessible for the series features presumably located on Tense ${ }^{0}$ and Asp ${ }^{0}$ heads merged higher in the tree. Therefore, the verb 'give' can have a suppleted form in the Future, Aorist, and the Perfective series. Thus, the derivation of the final structure proceeds piecemeal until the merger of VoiceP or some higher projection of the left periphery, and it is the Voice ${ }^{0}$ head that sends off the complement for the PF processing. Thus, all examples in (16)-(17) comply to the locality constraints defined in cyclic-theoretic terms, which as a minimum exceed the XP boundary due to the functional heads merging above the roots that license the argument structure of at least two NPs. This evidence cannot be accommodated within the Bobaljik's theory of root allomorphy which argues that the interaction between the root and the suppletion-triggering element is only possible within the same XP where the root merges. Thus, Bobaljik's generalization is not strong enough to cover the cases of suppletion evidenced above.

The last explanatory note will be about the series features that can be the trigger of the suppleted roots in the Future, Aorist, and Perfective series and their values. I propose the following feature set in the Table 2 that can be the trigger of the suppleted roots. Assuming that the Present series Present subseries screeves must have at least [+present] and [+imperfect] features which would distinguish the roots inserted in the environment of these features, the future, and Perfective series:

Table 2. Series and subseries features triggering the suppletion

\begin{tabular}{llll}
\hline Present & Series & Aorist Series & Perfect Series \\
\hline $\begin{array}{l}\text { Present Subseries } \\
\text { [+present] }\end{array}$ & Future Subseries & {$[+$ past] } & [+present $]$ \\
[-perfective] & [-past] & {$[ \pm$ perfective $]$} & [+perfective]
\end{tabular}

It is the two different values (plus and minus) of the three features ( \pm present, \pm past, and

\pm perfective) that define the complex system of TAM features for the three series in Georgian, and we can argue that the feature combinations licensing the Future subseries, Aorist, and Perfect series respectively and those boldfaced features in (22) will be triggering the suppletion of the certain roots in the screeves of the named series. Thus, the following features in isolation are responsible for the suppletion across three series: $[ \pm$ present $],[ \pm$ past $]$, and $[ \pm$ perfective].

In the final analysis, we arrive at the generalization on the Cyclic Domain of Suppletion Trigger formalized in (21):

(21) For all suppleted roots, whether they are triggered by the internal argument number or TAM features, the possible triggers of root suppletion should be in the local cyclic domain with the roots, these local domains being an XP or an extended projection, and the suppletion triggers should be in the same derivational cycle with the root.

Thus, the interaction between the root allomorphs and the triggering element is possible within the XP domain, but 
crucially this domain may be within the $\sqrt{ } \mathrm{P}$ as in the case of the internal argument number but outside of the $\sqrt{P}$ when it comes to the TAM-triggered suppletion.

\section{Conclusions}

To summarize, the main suppletion patterns illustrated in the paper comply to the locality constraints defined in the literature but the paper diverges from Bobaljik's and Moscal's views on restricting these domains within the XP in which the word formation is complete. C \& H's analysis of node sprouting was shown to be occurring in the root merger with the Num ${ }^{0}$ head controlling the suppletion of the roots, and it is shown that the conditioning domain for the suppletion of roots should not be reduced to the XP boundary but rather to the merger of the cyclic head and/or XPs which are not derivationally closed off from the roots and sending their complements off for PF processing.

\section{References}

Arad, M. (2003). Locality constraints on the interpretation of roots: The case of Hebrew denominal verbs. Natural Language and Linguistic Theory, 21(4), 737-779.

Arad, M. (2005). Roots and Patterns: Hebrew Morpho-syntax. Dordrecht: Springer.

Aronson, H. (1990). Georgian: A reader's grammar. Columbus, OH: Slavica Publishers.

Bejar, S. (2003). Locality, Cyclicity, and Markedness in Georgian Verbal Morphology. MS, University of Toronto.

Bobaljik, J. (2008). Where's Phi? Agreement as a post-syntactic operation. In Phi-theory: Phi-features across modules and interfaces, eds. Adjer, D., Bejar, S. and Harbour, D., 295-240. Oxford: OUP.

Bobaljik, J. (2012). Universals in comparative morphology. Cambridge and London: MIT Press.

Bobaljik, J., \& Harley, H. (2017). Suppletion is local: Evidence from Hiaki. In The structure of words at interfaces. (eds.) Heather Newell, Maire Noonan, Glynne Piggot, \& Lisa Travis. Oxford: OUP.

Choi, J., \& Haley, H. (in press). Locality domains and morphological rules: Phases, heads, node-sprouting, and suppletion in Korean honorification. MS. University of Arizona.

Chomsky, N. (1995). The Minimalist Program. Cambridge, MA: MIT Press.

Chomsky, N. (1999). Derivation by phase. MIT Working Papers in Linguistics, 18, 1-43.

Chung, I. (2009). Suppletive verbal morphology in Korean and the mechanism of vocabulary insertion. Journal of Linguistics, 45(03), 533-567.

Cinque, G. (1999). Adverbs and Functional Heads: A Cross-Linguistic Perspective. Oxford: Oxford University Press.

Embick, D. (2010). Localism versus globalism in morphology and phonology, Cambridge, MA: MIT Press.

Embick, D., \& Halle, M. (2005). On the status of stems in morphological theory. In Proceedings of going Romance. T. Geertz \& H. Jacobs (eds.). Amsterdam, Philadelphia: John Benjamins.

Halle, M., \& A. Marantz, A. (1993). Distributed Morphology and pieces of inflection. The View from Building, 20, $111-176$.

Harley, H. (2011). On the identity of roots. MS, University of Arizona, Tucson. Available at: http://ling.auf.net/lingBuzz/001527

Harley, H. (2014). Reply to commentaries "On the identity of Roots. Theoretical Linguistics, 40(3/4), 447-474.

Harley, H. (2015). Suppletion, agreement, reduplication readjustment: Making number on Hiaki roots. Invited Talk. Chicago Linguistics Society Meeting 51, April 23 ${ }^{\text {rd }}-25^{\text {th }}, 2015$, p.10.

Harley, H., Tubino-Blanco, M., \& Haugen, J. (2009). Applicative Constructions and suppletive verbs in Hiaki, Rice Working Papers in Linguistics, 1, 42-51.

Harley, H., Tubino-Blanco, M., \& Haugen, J. (2016). Locality conditions on suppletive verbs in Hiaki. In The morphosyntax-phonology connection: Locality and directionality at the interface. Eds. V. Gribanova and S. Shih. Oxford: OUP.

Harris, A. (1981). Georgian Syntax. Oxford: Oxford University Press.

Kajaia, O. (2001). Megrul-Kartuli leksikoni. [Mengrelian-Georgian Dictionary]. Tbilisi, Georgia: Nekeri.

Kratzer, A. (1996). Severing the external argument from its verb. In Phrase structure and Lexicon, eds. J. Rooryck \& 
Zaring, L., 109-137.

Lomashvili, L., \& Harley, H. (2011). Phases and templates in Georgian agreement. Studia Linguistica 65: 223-267.

Marantz, A. (1997a). No escape from syntax: Don't try morphological analysis in the privacy of your own lexicon. In Proceedings of the $21^{\text {st }}$ Annual Penn Linguistics Colloquium, ed. A. DIMIDRIADIS, et al., 201-225. Pennsylvania Working Papers in Linguistics 4.2. Philadelphia: University of Pennsylvania, Penn Linguistics Club.

McGinnis, M. (2001). Phases and the syntax of applicatives. Available at: http://minimalism.linguistics.arizona.edu/AMSA/PDF/AMSA-187-0101.pdf

McGinnis, M. (2016). The Morphosyntax of thematic affixes in Georgian. A Talk presented at the South Caucasian Chalk Circle Workshop, University of Chicago Center, Paris, France.

Moscal, B. (2015a). Limits on allomorphy: A case study on nominal suppletion, Linguistic Inquiry, 46(2), 363-376.

Moscal, B. (2015b). Domains on the border: Beween morphology and phonology. PhD Thesis, University of Connecticut: Storrs.

Nash Harran, L. (1992). On the BE and HAVE in Georgian. MIT Working Papers in Linguistics 22, (ed.) Harley, H., 153-171. Cambridge, MA: MIT Press.

Pylkkannen, L. (2002). Introducing arguments. PhD Dissertation, MIT.

Slobodchikoff, T. (2009). Hopi Suppletion: A phase-theoretic account. Talk presented at LASSO meeting, BYU, Utah: Provo.

Veselinova, L. (2003). Suppletion in verbal paradigms: bits and pieces of a puzzle. Stockholm, Sweden: Stockholm University.

Veselinova, L. (2006). Suppletion in Verbal Paradigms: bits and pieces of the puzzle. Amsterdam, Philadelphia: John Benjamins. 